NBER WORKING PAPER SERIES

\title{
DOES IN UTERO EXPOSURE TO ILLNESS MATTER? THE 1918 INFLUENZA EPIDEMIC IN TAIWAN AS A NATURAL EXPERIMENT
}

\author{
Ming-Jen Lin \\ Elaine M. Liu \\ Working Paper 20166 \\ http://www.nber.org/papers/w20166
NATIONAL BUREAU OF ECONOMIC RESEARCH
1050 Massachusetts Avenue \\ Cambridge, MA 02138
}

May 2014

Contacting author. Email: mjlin@ntu.edu.tw. We thank Jerome Adda, Josh Angrist, Alan Barreca, Dan Bennett, John Bonin, Ken Chay, Aimee Chin, Willa Friedman, Seema Jayachandran, Ted Joyce, Ted Miguel, Tom Vogl, and conference participants at NBER-SI Health Economics Session, PacDev, NEUDC, MIEDC, AEA, and Academic Sinica and seminar participants at LSU, SFU, Texas A\&M and the Center for Chinese Agricultural Policy for their helpful comments and suggestions. Financial support from the National Science Council, Taiwan (NSC99-2410-02-250-MY2) is appreciated. We thank Jason Chien-Yu Lai and Tzu-Yin Hazel Tseng for their excellent research assistance. We thank Ian Downing for his careful editorial support. The views expressed herein are those of the authors and do not necessarily reflect the views of the National Bureau of Economic Research.

NBER working papers are circulated for discussion and comment purposes. They have not been peerreviewed or been subject to the review by the NBER Board of Directors that accompanies official NBER publications.

(C) 2014 by Ming-Jen Lin and Elaine M. Liu. All rights reserved. Short sections of text, not to exceed two paragraphs, may be quoted without explicit permission provided that full credit, including $\odot$ notice, is given to the source. 
Does in utero Exposure to Illness Matter? The 1918 Influenza Epidemic in Taiwan as a Natural Experiment

Ming-Jen Lin and Elaine M. Liu

NBER Working Paper No. 20166

May 2014

JEL No. I12,I19,N35

\begin{abstract}
This paper tests whether in utero conditions affect long-run developmental outcomes using the 1918 influenza pandemic in Taiwan as a natural experiment. Combining several historical and current datasets, we find that cohorts in utero during the pandemic are shorter as children/adolescents and less educated compared to other birth cohorts. We also find that they are more likely to have serious health problems including kidney disease, circulatory and respiratory problems, and diabetes in old age. Despite possible positive selection on health outcomes due to high infant mortality rates during this period (18 percent), our paper finds a strong negative impact of in utero exposure to influenza.
\end{abstract}

Ming-Jen Lin

Department of Economics

National Taiwan University

21 Hsu-Chow Road, Taipei (100)

Taiwan

mjlin@ntu.edu.tw

Elaine M. Liu

Department of Economics

University of Houston

McElhinney Hall 223D

Houston, TX 77004

and NBER

emliu@uh.edu 


\section{Introduction}

The fetal origins hypothesis proposed by Barker in 1992 posits that "certain chronic conditions later in life can be traced to the course of fetal development.” There is some evidence in the medical literature suggesting that poor fetal conditions can increase the risk of schizophrenia (Brown et al. 2004) and cardiovascular disease and hypertension (Barker 1990, 1998; Langley-Evans 2001). However, it is not an easy task to establish a causal link between the in utero environment and long-term outcomes. For example, there could be unobserved characteristics of mothers or families associated with the poor in utero environment, which could also have an impact on one's long-term outcomes. To tackle this identification issue, Almond (2006) investigates the long-term impact of the 1918 influenza pandemic in the United States. The sudden, unexpected and brief nature of the 1918 influenza pandemic sets up a natural experiment to test the fetal origins hypothesis. He shows that cohorts in utero during the peak of the influenza pandemic exhibited lower educational attainment, lower income, lower socioeconomic status, a higher physical disability rate, and higher welfare income compared with the adjacent cohorts. Almond also uses maternal mortality rates as a proxy for the severity of the pandemic and finds that those who were born in more highly affected areas were less educated.

Building on Almond's work, this paper employs a similar empirical strategy but with Taiwanese datasets. Taiwan was a colony of Japan between 1889 and 1945, and the Japanese colonial government compiled detailed regional-level and aggregate-level data that includes pandemic severity, mortality, and government expenditure on public health and education. It was estimated that nearly 770,000 people (1/5 of the total population) contracted the influenza strain, and influenza had a mortality toll in Taiwan of about 25,000 people in 1918 (Ding 2008).

There are a few features about Taiwan that make it an interesting case in which to test the fetal origins hypothesis. During the Colonization, Taiwan suffered from very high infant mortality rates (16-18 percent), ${ }^{1}$ and nearly 25 percent of newborns did not live past five years. With the presence of other

\footnotetext{
${ }^{1}$ Among works that examine the 1918 influenza pandemic-i.e., Neelsen and Stratmann (2012) in Switzerland, Nelson (2010) in Brazil, Mazumder et al. (2010) and Almond (2006) in the United States_Taiwan is the worst
} 
infectious diseases such as plague, cholera, and malaria, the environment in Taiwan was much less salubrious than that of the United States or most other countries that have been used to test the fetal origins hypothesis. The finding in this paper is of high relevance to present-day sub-Saharan Africa and other developing countries with high infant/child mortality rates and various infectious diseases. The surviving pandemic cohorts in Taiwan could be healthier than non-pandemic cohorts if the selection effect (i.e., the culling of the weakest) dominates the scarring effect of the flu (Bozzoli, Deaton, and Quintana-Domeque 2009). Thus, whether we find a negative outcome among those who were in utero during the influenza outbreaks becomes an empirical question.

We also make a few specific contributions to the literature:

1. Compared to the previous literature, we provide a comprehensive picture of health and cognition outcomes over the lifecycle of the relevant birth cohort. We utilize a historic dataset from the 1920s and 1930s to provide a snapshot of the pandemic-affected cohorts' height in pre-teen and teenage years. Height is particularly interesting since several studies suggest that adult height can depend in part on in utero environment (Ericson and Kallen 1998; Hack et al. 2002) and height is found to be associated with one's cognitive ability and labor market outcome (Case and Paxson 2008). We follow the same cohorts into the 1980s, and use the 1980 census to examine educational attainment. ${ }^{2}$ In addition, the 1989 Survey of Health and Living Status of the Elderly was used to examine a wide set of long-term health problems, including

environment of all, in terms of economic conditions and disease. For example, if we compare the education of the cohorts born during this period, Switzerland has a 17.5 percent rate and the United States has about a 22 percent rate of cohorts who completed high school and beyond, while Taiwan has only a 6.5 percent rate. Brazil has a 5.5 percent rate of this cohort that had completed college education, while only 1.5 percent of the Taiwanese cohorts completed college. Hospital conditions in Taiwan were harsh. There were approximately 0.21 physicians per 1,000 people in the 1920s, compared to approximately 1.3 physicians per 1,000 people in the United States (Census Bureau 1924). According to Tsai (2005), the mortality rate conditional on influenza infection is 3.3 percent in Taiwan in 1919, higher than the 2.5 percent mortality rate in the United States and 1.21 percent in Japan.

${ }^{2}$ The 1980 census does not provide direct income nor wealth measures. However, it provides other outcomes including labor force participation and housing conditions. Neither of these outcomes is appropriate for our analysis since the relevant birth cohorts (1919) were 60, which is older than the average retirement age in Taiwan, 55. Thus, it is unclear whether remaining in the labor force at age 60 is in fact desirable. On one hand, those who have been able to accumulate more wealth may retire earlier; on the other hand, the less healthy may also retire early. As for the housing outcome, it is the norm in Taiwan that the elderly live with and are supported by their children upon retirement. Housing is a common form of inheritance. One's housing condition may not only reflect the relevant cohorts' wealth, but may also reflect one's family wealth (be it one's father's, or his children's, wealth). The regression results with these outcomes are available in the web appendix posted on the authors' homepage. 
heart disease, respiratory problems, and diabetes. ${ }^{3}$

2. In many parts of the world (including the United States, Europe, and Japan), there were two waves of influenza in 1918 and in 1920 (Erkoreka 2010; Johnson and Mueller 2002; Richard et al. 2009). To our knowledge, among the literature examining the long-term impact of the 1918 influenza pandemic, none of these works have exploited the second wave of influenza. In Taiwan, although the second wave had higher death tolls than the first (see Figure 1 for influenza-related death tolls), only 5-8 percent of the total population contracted influenza during the second wave, as opposed to 20 percent in the first wave (Taiwan Medical Association Journal 1921). The increase in second wave deaths tolls compared to the first wave was driven mostly by the very young and the very old. The second wave (1920) did not impact as many childbearing-age women as much as the first wave did (See further discussion in Section III and Figure 2). The considerable variation in influenza prevalence between the two waves provides us an additional check to compare the outcomes of cohorts who were in utero during the first wave to those who were in utero during the second wave.

3. Better identification of treated cohorts. Using the US 1960-1980 Censuses, Almond (2006) has to infer one's birth year based one's age and quarter of birth (but not the year of birth). Age-heaping is a known problem in the US census: i.e., those born in 1919 could report age 40 rather than age 41 in the 1960 census, leaving the birth year for some to be incorrectly identified (Lleras-Muney, 2005). This issue of ageheaping could possibly bias the results downward. In the Taiwanese census, birth date is recorded by interviewers who verify one’s identification card or hukou (household registration), so age-heaping would not be an issue (Taiwan Census Report 1980).

4. Due to a lack of Taiwanese involvement in World War I (WWI) and controlling for a detailed set of parents' characteristics, we are able to avoid a challenge to Almond's work that has been recently raised by Brown (2011), regarding US involvement in WWI (July 1914-Nov 1918). Using the 1920 and 1930 US

\footnotetext{
${ }^{3}$ Most of the papers in the literature examine one dimension of either long-term health or the socioeconomic effects of in utero exposure to the pandemic. For example, Almond and Mazumder (2005) considered a limited set of elderly health outcomes using the Survey of Income and Program Participation, which is not designed for health. Both Mazumder et al. (2010) and Garthwaite (2009) use the National Health Interview Survey, but neither can examine respiratory illnesses due to data limitation.
} 
censuses, Brown (2011) finds that parents of the 1919 birth cohort are less educated, of lower socioeconomic status, and older than the parents of surrounding cohorts. Since Almond does not control for parents' characteristics in his work, the time series estimates of the coefficient on 1919 could overstate the true effect of the pandemic. ${ }^{4}$ In contrast, as a Japanese colony, Taiwan had no official involvement in WWI to our knowledge (Chou 1995).

Since we do not know whether one's mother caught the flu, and we cannot simply compare those who were exposed to flu in utero to those whose were not. We first compare outcomes of those who were born in 1919 and 1920 (thus in utero during flu pandemics) to those of adjacent birth cohorts and infer that the deviation of these outcomes from a linear trend could be a result of flu pandemic. We find that the 1919 birth cohort received 0.08 fewer years (2.5 percent) of education and that those who were born in 1920 received 0.04 fewer years compared to the adjacent birth cohorts.

While this effect may seem small, we would remind our readers of the following: First, it was estimated that about 20 percent of the total population caught the flu during the first wave, so the negative effect we observed in the entire birth cohort is being driven by only the 20 percent of the population who were exposed to the flu in utero. A simple back-of-envelope calculation would suggest that the impact on those whose mothers were exposed to the flu would be 0.4 fewer years (12 percent) less education. ${ }^{5}$ Second, given that cohort attrition would tend to reduce estimated effects, if weaker cohort members are less likely to survive until 1980 as a result, then a negative effect would be estimated in a positively selected sample. A simple calculation suggests that the 1919 birth cohort is about 3 percent smaller than the 1918 birth cohort in the 1980 census. After applying Lee’s (2009) bounding method, the coefficient on 1919 would be -0.13 years (as opposed to -0.08 years). ${ }^{6}$ Lastly, the infant mortality and child mortality

\footnotetext{
${ }^{4}$ This issue should not have much impact on the parts of Almond's (2006) findings that are derived from regional variation in pandemic severity.

${ }^{5}$ This exercise is similar to any policy evaluation in which only the effect of treatment-on-the-treated (TOT) equals the effect of the intent-to-treat effect divided by the take-up rates. In comparison, Almond finds that those born in 1919 in the United States receive nearly 1 percent fewer years of education for males and 0.6 percent fewer for females than the surrounding cohorts (based on the 1980 census estimates).

${ }^{6}$ The exercise is based on a couple assumptions: the cohorts of the 1919 group is 3 percent smaller compared to adjacent birth cohorts; and among people who were born in 1919, those who did not survive until the 1980 census
} 
rates ( 25 percent) were much higher in Taiwan than in the United States during this period. Thus, the scarring effects of the pandemic must be quite strong in order to dominate this strong selection effect and still be detectable. In summary, we have justification to believe that the negative effects of the pandemic in Taiwan are even greater than those found in Almond (2006).

We also find that the impact on the 1919 birth cohort is greater than the impact on the 1920 birth cohort. It is not surprising given that the influenza was not as widespread in the second wave. We compare the trimester during which one was exposed to influenza and found that it does not have differential impact on health.

Next we exploit regional variations in the flu pandemic by using the maternal mortality rates at region-year level as a proxy for one’s exposure to influenza. There were 12 administrative regions in 1919. To deal with the small clusters issue (Angrist and Pischke 2008, pp 319), we employ the wild bootstrap technique proposed by Cameron, Gelbach, and Miller (2008). During the peak of the pandemic, the maternal mortality rate increased by 0.4 percentage points. We find that every 0.4 percentage point increase in maternal mortality rate reduces the years of schooling by 10 percent ( 0.36 year) and reduces height by $1.6 \mathrm{~cm}(\sim 0.6$ inch) or 0.6 standard deviations. Our evidence is consistent with the medical literature's finding that in utero influenza can increase the risk of diabetes, respiratory diseases, and kidney disease (Langley-Evans 2001; Konje et al. 1996), and is also similar to Almond and Mazumder’s (2005) findings. Given the scarcity of long-run data linkage between in utero individuals and their subsequent developmental outcomes many years later, our results shed new light on the validity of the fetal origins hypothesis.

One might worry that since the influenza pandemic occurred in other parts of the world during the spring of 1918, it is possible that some people could have avoided pregnancy in expectation of the influenza pandemic's arrival in Taiwan. In this regard, we provide several pieces of evidence to the contrary. First, the articles and newspapers we surveyed suggest that the severity and extent of the spread

were the least educated ones. Therefore we drop 3 percent of the least educated population from the adjacent birth cohorts (excluding 1919/1920) and re-estimate the effect of being born in 1919 and 1920. 
of influenza in October and November of 1918 were a shock to both the colonial Japanese government and the media. In fact, Ding (2008) specifically suggests that the Japanese colonial government was slow to react to the influenza's arrival and to contain the flu outbreak in the crucial period because the government did not anticipate that it would be a severe pandemic. Second, if better-informed parents (e.g. civil servants or Japanese) systematically avoided pregnancy during this period, we could have an overestimate of the true impact of the pandemic. Using the birth data collected by the Japanese colonial government, we compare birth rates and birth frequencies by the father's residency ${ }^{7}$ and field of employment between the pandemic cohorts and surrounding cohorts, and we do not find any difference. Continuing this thread of inquiry, we also investigate the possibility that the second wave of influenza in Taiwan could have been expected by further excluding the 1920 birth cohort from our analysis as a robustness check, and the results remain robust.

Another concern is that the spread of the pandemic could be correlated with other factors, e.g., poor sanitation and poor economic development in an area, which could be predictive of later-life health and human capital outcomes. The spread of influenza in Taiwan is believed to have started in a northern port city and spread along the railroad in less than two weeks. Thus, regions with higher influenza-related mortality are in fact those regions with higher income and higher spending on education and sanitation infrastructure both in 1918 and in later years. ${ }^{8}$ This positive relationship could bias our estimates toward zero. In the robustness check section, we control for health and education spending at the regional level and find similar results.

The paper proceeds as follows: Section II reviews the literature. Section III describes the impact of the 1918 influenza on Taiwan and the datasets used in the paper. Section IV provides empirical results, and Section V concludes.

\footnotetext{
${ }^{7}$ Residency is recorded either as mainlander (Japanese) or local (Taiwanese) and field of employment includes agriculture, transportation, fishery, mining, industry, commercial, government, others, unemployed, and housework. 8 This phenomenon is also known as urban penalty. See Haines (2001) for a discussion of the existence of urban penalty in the US. For brevity, we report the correlation matrix between health/education expenditure and pandemic severity in the web appendix.
} 


\section{Literature Review}

Research has shown that early life shocks could have long-lasting effects on various developmental outcomes into adulthood (Almond and Currie 2011a; Case et al. 2002, 2005). ${ }^{9}$ For a detailed introduction to this literature, please see Almond and Currie (2011a, 2011b) and Currie and Vogl (2013). Epidemiologists used to believe that the placenta was a perfect filter, resulting in the belief in the 1950s that smoking and drinking were fine for pregnant women (Almond and Currie 2011b). Barker (1992) first formalized this conjecture by proposing the fetal origins hypothesis, which argues that inadequate in utero nutrition could program a fetus to prioritize brain growth at the expense of other organs and tissues. As a consequence, certain chronic health conditions such as diabetes and heart problems in old age can be traced back to the fetal environment. Ozanne and Hales (2004) support this hypothesis by providing experimental results on mice. ${ }^{10}$ Barker et al. (2002) also finds that this "thrifty phenotype"-i.e., slow fetal growth followed by fast catch-up later, predicts large differences in the cumulative cases of coronary heart disease, type 2 diabetes, and hypertension. There is also epidemic evidence showing that poor early fetal conditions increase the risk of schizophrenia (Brown et al. 2004), kidney disease, and high blood pressure (Langley-Evans 2001).

\section{Influenza as a Natural Experiment to Test the Fetal Origins Hypothesis}

Overall, the literature uses large and sharp pandemics (e.g., the 1918 and 1957 influenzas) as natural experiments to test the fetal origins hypothesis. ${ }^{11}$ The identification strategies are either to compare the

\footnotetext{
${ }^{9}$ These researchers find profound short-run impacts of low birth weight (LBW) such as higher hospital costs and higher infant mortality (Almond et al. 2005; Black et al. 2007; Oreopoulos et al. 2008), and the long-run effects of LBW include lower test scores and below-average IQ and education (Black et al. 2007; Boardman et al. 2002; Conley and Bennett, 2000; Hack et al. 2002; Johnson and Schoeni 2011, Lin and Liu 2009; Oreopoulos et al. 2008; Royer 2009). Other effects include lower wages and even shorter height (Behrman and Rosenzweig 2004; Black et al. 2007; Johnson and Schoeni 2011). Twins data or instrumental variables method are used to solve the potential endogeneity problem caused by omitted bias.

${ }^{10}$ They found that the lifespan of experimental mice is considerably shortened if the postnatal period of growth is accelerated to make up for reduced growth in utero. In addition, these mice are susceptible to the adverse effects on longevity of an obesity-inducing diet after weaning.

${ }^{11}$ Barreca (2010) uses exposure to malaria to study the disease’s impact; McEniry and Palloni (2010) study variation in harvest season to study the nutritional impact; Field, Robles, and Torero (2009) study in utero exposure to an iodine intervention program; Almond and Mazumder (2011) examine the impact of Ramadan observance during
} 
outcome difference between exposure and its surrounding cohorts (Almond 2006; Garthwaite 2009; Nelson 2010), or to use regional variation in influenza severity (Kelly 2011; Neelsen and Stratmann 2012) or in maternal mortality rate to impute the impact on fetus (Almond 2006). There are a few possible reasons why in utero exposure to influenza can affect the outcome of the child. Kawana et al. (2007) use records from an army hospital in Japan and find that nearly half of the patients report that they lost appetite, and a quarter reported vomiting and diarrhea during the influenza pandemic. Thus, the influenza outbreak can also affect pregnant women as well as the fetus's nutritional intake. Other than the nutritional channel, more recently the medical literature has suggested that even if the viruses may not directly damage the fetus, the mother's inflammatory responses and stress can also affect the child's outcome. For example, Atladóttir et al. (2010) and Patterson (2011) both link maternal inflammatory responses (to the virus) to the child's likelihood of autism. Huizink et al. (2003) and LeWinn et al. (2009) both find a negative association between maternal cortisol levels and child motor development and IQ. ${ }^{12}$

Almond (2006) and Almond and Mazumder (2005) were among the first to test the fetal origins hypothesis using a natural experiment. The 1918 influenza pandemic was a widespread negative shock that spanned four months in the United States. Almond (2006) and Almond and Mazumder (2005) compare the outcomes of the cohorts in utero during the peak of the influenza pandemic (i.e., those born in 1919) to the surrounding cohorts. They find that the 1919 birth cohort suffered from lower educational attainment, income, and socioeconomic status, as well as higher physical disability rates and higher welfare income as adults, relative to the bookended cohorts (those born just earlier and later). Almond finds that cohorts born in states with more severe exposure to the influenza pandemic experienced significantly worse outcomes than those born in states with less severe exposure. Using the National Health Interview Survey (NHIS) in

pregnancy; Chen and Zhou (2007) study Chinese famine; and Neelsen and Stratmann (2011) study the Greek famine. A paper by Almond, Edlund and Palme (2009) uses radioactive fallout from the Chernobyl incident to examine school outcomes. Ward (2011) studies the long-term outcomes of the school immunization mandate in Canada.

${ }^{12}$ Several other papers use natural experiments such as earthquakes (Glynn et al. 2001; Torche 2011)or the harassment in California of Arab and Arab-American women after the September 11, 2001 terror attacks (Lauderdale 2006) to examine the impact of exogenous maternal shock and childbirth outcomes. In the case of using the influenza pandemic as a natural experiment, it is likely that pregnant women also experience maternal stress and possibly have inflammatory responses as a result of influenza; thus, we cannot distinguish which channels affect one's outcomes. 
the United States, Garthwaite (2009) finds that 1918 flu pandemic cohorts, defined by those born in the fourth quarter of 1918, and the first and second quarters of 1919, have a higher probability of developing coronary heart disease, diabetes, kidney disorders, or reporting poor health. Nelson (2010) finds similar adverse effects in education and wages for those who were born in the 1919 exposure cohort in Brazil. Neelsen and Stratmann (2012) find the same long-term effect on the pandemic cohort in Switzerland. Finally, using another influenza pandemic, i.e., the 1957 Asian flu in Great Britain, Kelly (2011) finds that the epidemic density has a negative effect on test scores, birth weight, and height for those who were in utero during the influenza. Compared to these other papers testing the fetal origins hypothesis, the setting of this paper-Colonial Taiwan in 1919-was among the worst environments in terms of disease and nutrition. During this period, Taiwan was plagued with malaria, cholera, typhoid, plague, and flu. About a quarter of those who were born in the 1920s never lived past one year. Following Bozzoli, Deaton, and Quintana-Domeque (2009), given the high mortality rates, the selection effect (i.e., the culling of the weakest) could possibly dominate the scarring effect; thus, it is unclear whether the net effect of the flu pandemic would be negative.

\section{The 1918-1920 Influenza Epidemic in Taiwan and the Datasets}

\section{Background}

The 1918 influenza, also known as the Spanish Flu, was one of the most lethal pandemics in human history, claiming more than 20 million lives worldwide (Ansart 2009; Johnson and Mueller 2002). The basic symptoms of those who contracted the influenza included loss of appetite, fever, vomiting, and headache (Kawana et al. 2007).

The epidemic first entered Taiwan through a port city in northern Taiwan in late October 1918, then spread along the railway from north to south in the heavily populated western plain within two weeks. Sparsely populated eastern Taiwan was affected much less by the pandemic since regional transportation at that time was still poorly developed (Ding 2008). The most severely affected regions were areas with better economic development and areas with higher public expenditure. The more developed places in 
1918 are also places with better development in economic and health infrastructure even today. Therefore, it is possible that our estimates of the impact of influenza could be underestimated due to the inverse relationship between government investment and pandemic severity.

Taiwan was a Japanese colony from 1895 to 1945. The Japanese colonial government that ruled Taiwan during that time collected vital statistics for the entire Taiwanese population, including the cause of deaths, and published aggregated-monthly and annual regional records in the publication Dynamic Census of the Taiwanese Population. We present the aggregate level of influenza-related death tolls from 1916 to 1926 by quarter in Figure $1 .^{13}$ Scholars who specialize in colonial Taiwanese history generally divide the 45-year Japanese colonization into three periods: 1895-1915, 1916-1936, and 1937-1945. They all suggest that 1916 is the beginning of a new era because it marked the end of the 20-year period of armed resistance by the Taiwanese and a sharp increase in government expenditures (Ru 2010; Rubinstein 1999, p. 212). Between 1912 and 1915, there was a slight increasing trend in maternal mortality rates, and a downward trend from 1916 onward. We decided to exclude pre-1916 data in our analysis for these reasons. In Figure 1, it shows that the second wave of influenza had higher mortality tolls than the first wave.

[Figure 1 inserts here]

For the purpose of our analysis, we would like to know how each wave of influenza affects childbearing age women. In Figure 2, we present the female influenza-related death tolls by age. One can see that the increased death tolls in the second wave (1920) were driven by the deaths of those under age 20 and above age 70. The death tolls were lower for child-bearing age (ages 25-35) women in the 1920 pandemic than in 1918. Combining this stylized fact, along with the fact that the infection rate is lower in the second wave than the first wave (imputed based on the statistics provided in the Taiwan Medical Journal 1919 \& 1921), we can infer that fewer childbearing age women were affected in the second wave than the first wave.

\footnotetext{
${ }^{13}$ Since it is highly likely that influenza could be misdiagnosed as other respiratory diseases in 1918, following Johnson and Mueller's methodology (2002), we also code other causes of death such as tuberculosis, acute bronchitis, chronic bronchitis, pneumonia, pertussis, and diphtheria with influenza as influenza-related deaths. The trend for influenza-related deaths moves closely with deaths by influenza only.
} 


\section{[Figure 2 inserts here]}

Ideally, we would want to use region-year variation in maternal infection rate, but such data are not available. As Almond (2006) has argued, maternal mortality rate is the best proxy available for measuring the severity of the effect of influenza on a fetus. First, the age distribution of influenza victims varies across regions and time. Using data in the United States, Noymer and Garenne (2000) find that outbreaks in 1918 were most deadly to the very young, very old, and, surprisingly, those at the prime age of between 25 and 35. ${ }^{14}$ A similar pattern has been found by Richard et al. (2009) using data in Japan. In the data available to us, we find a very similar pattern for the 1918 influenza. In order to assess fetal origins effects, only measures of pandemic intensity among those of childbearing age are relevant. We do not have a further breakdown of the pandemic intensity by age group-region; thus, maternal mortality could better capture this aspect of pandemic intensity. Second, Noymer and Garenne (2000) note that males were more likely to die in the influenza pandemic, hence data for the mortality of young women are needed so the estimation will not be confounded by the excess male deaths. ${ }^{15}$ Third, puerperal death would not have been misdiagnosed, as it did not resemble other causes of death, as did other major pathological illnesses during the pandemic. Finally, maternal mortality has previously been used as a proxy for the in utero health environment. For example, Barker and Osmond (1987) found a strong relationship between local maternal mortality rate and the stroke mortality of offspring.

We first examine whether maternal mortality rates and the flu pandemic exhibit similar patterns. During this period, the occurrence of other infectious disease outbreaks such as malaria and cholera could also have caused an increase in the maternal mortality rate (MMR). Thus, in Figure 3 we present the residual MMR estimated from a regression controlling for the malaria death tolls, cholera death tolls, and a quadratic time trend. One thing worth noting is, as we hypothesized earlier, that the second wave impacted

\footnotetext{
${ }^{14}$ For example, when the influenza first hit Taipei (the first major city with a reported influenza incident), public gatherings such as religious and school activities still took place as usual, and it was noted in the news that the influenza was spread among students in several elementary schools in Taipei. By December 1918, many public gatherings were cancelled. It is evident that infectious rates could have specific age/gender profiles depending on localities.

${ }^{15}$ If we were to use the influenza death tolls or influenza mortality rates as a proxy for in utero exposure to influenza, this is a measurement error issue in the right-hand-side variable, which could bias estimates downward.
} 
fewer childbearing age women than the first wave and that the MMR has a smaller spike in the second wave than the first wave. This pattern is interesting since in later regressions we indeed find that the impact of the first wave of influenza is indeed smaller than the impact of the second wave. ${ }^{16}$

\section{[Figure 3 inserts here]}

\section{Anthropometric Outcome during Elementary School/Middle School}

A series of Taipei County’s Statistical Books, 1929-1938, document the average height for male students from age 13 to 17 for each year. This allows us to examine the average height of the pandemic cohort during the teenage years relative to other cohorts. The Japanese colonial government also recorded the height of all students in 1927 and published "Health Statistics for School Students.” For each region and each age, we know how many school kids fall into each of the 2.5-centimeter height bins by gender. These historic measures allow us to exploit the regional variations in pandemic severity.

\section{Educational Attainment in the 1980 Census}

The 1980 Census of Taiwan records the educational attainment, gender, birthplace/ancestral home (huji), birth date, and birth year for all Taiwanese alive in 1980. To determine the effect of the 1918 influenza outbreak, we can link the severity of the epidemic, indicated by maternal mortality and infant mortality rates at the time and the region of an individual's birth, to one's subsequent educational attainment. We drop all the samples that were not born in Taiwan since there was a massive migration in 1949 from China. ${ }^{17}$ Table 1 shows the summary statistics of educational attainment taken from the 1980 census for those who were born between 1916 and 1926. On average, this cohort has 3.25 years of schooling, and males (4.73 years) completed significantly more years of schooling than did females (1.9 years). Furthermore, the average MMR and infant mortality rate are 0.47 percent and 16.55 percent, respectively. These region-year-level variables, which can approximate the average economic, social, educational, and sanitary conditions, will be used in the regressions later.

\section{[Insert Table 1 here]}

\footnotetext{
${ }^{16}$ If we regress the MMR residual on influenza death tolls, the coefficients on influenza tolls is significant at the $1 \%$ level. The raw MMR figure is presented in the web appendix.

${ }^{17}$ The 1918 influenza also affects China, so we cannot use the immigrants from China as a comparison group.
} 


\section{Health Outcome in 1989}

We use data from the 1989 Survey of Health and Living Status of the Elderly in Taiwan, which records the health conditions for those who were above 65. It contains information on gender, father's education and occupation, birth year, birth county (which we can then merge to the birth region), and most important of all, whether sample individuals have health problems from a list of disease categories common among the elderly.

\section{Empirical Results}

Health Attainment-Height in Childhood and Adolescents

Height for age is widely considered as a long-run measure of nutritional status (Thomas 1994). Although the treatment here (in utero exposure to influenza) was not specifically about nutrition, as we discussed in the literature review, symptoms of the 1918 influenza pandemic include appetite loss, vomiting, and/or diarrhea, all of which can affect the mother's and fetus's nutritional intake, and thus affect one's height.

Our first evidence comes from Taipei County’s Statistical Book, 1929-1938, which documents the average height for male students from age 13 to 17 in each year. This allows us to back out the average height for those who were born from 1916 to 1921 , then trace their average height from age 13 to $17 .^{18}$ Figure 4 reports the results. Readers should be cautious when they interpret this figure since the average years of education among males in Taipei County for these birth cohorts was about 5 years ( age 12). Therefore Figure 4 only reflects the height for a selected population who were still in school between age 13-17. Given this positive selection, we find that the average heights of male students born in 1919 were similar to the adjacent cohorts at age 13, and the height gap widens at ages 14-16. At age 16, the 1919 birth cohort was $3.5 \mathrm{~cm}$ (1.38 inches) shorter than their surrounding cohorts. By age 17, the difference in height between the 1919 and 1920 birth cohorts was $1 \mathrm{~cm}(0.39$ inch). Another interesting pattern is that the 1919

\footnotetext{
${ }^{18}$ For example, a person who is age 14 in the 1931 statistical book should have been born in 1917.
} 
birth cohort seems to experience adolescent growth spurts later than the rest of the surrounding birth cohorts. It is related to what Case and Paxson (2008) describe in their paper-children growing up with worse nutritional/disease environments experience later adolescent growth spurts. It is possible that while other birth cohorts experience growth spurts in age 14/15, the pandemic cohort catch up in terms of their heights in their late teens (at age 17). This same reason might explain why Mazumder et al. (2010) find a much smaller effect $(0.12 \mathrm{~cm})$ on adult height when comparing the 1919 birth cohort to the surrounding cohorts in the US data.

[Insert Figure 4 here]

Next, we use data from Health Statistics for School Students, 1927. This dataset include the number of male and female students in each of the height categories for each region, each age (thus, birth year) and it was measured when the 1919 pandemic cohorts were at age 8, thus lessening the selection issue compared to the data above. ${ }^{19}$ To gauge the effect of influenza on developmental outcomes, we explore the regional-time variations in influenza severity. ${ }^{20}$

We first regress height in centimeters on the MMR with age, gender, region fixed effect, infant mortality rate at region-birth year, and region-specific time trend, and later the results are stratified by gender. To find the corresponding MMR, we use an average of the regional MMR from the imputed birth year and the lagged regional MMR. For example, for those who are nine years old in region $j$, the corresponding MMR would be an average of the 1918 MMR and the 1917 MMR from region $j$. P-values from the wild bootstrap are reported in Table 2 in brackets. We convert height into z-score for height, so that it is easier to compare across age. Each 0.4 percentage point increase in maternal mortality would decrease the average height of Taiwanese male students by approximately $1.76 \mathrm{~cm}$, or 0.6 standard deviations. The impacts on girls' height are negative but statistically insignificant. Next we explore specific

\footnotetext{
${ }^{19}$ We include cohorts aged between 7 and 10 . We have chosen the cutoff age to be at age 10 since the average education level was about 3.3 years of education. Beyond age 10, the selection issue can be more serious.

${ }^{20}$ This specification is modeled after Almond's working paper version (2005). We also try to replicate Almond (2006) in imputing maternal infection rates using the MMR for 1917, 1918, and 1919. Almond uses the following formula: maternal infection rate ${ }_{1918}=\left(\mathrm{MMR}_{1918}-\mathrm{MMR}_{1917}\right) /\left(\right.$ maternal morbidity rate $\left.-\mathrm{MMR}_{1917}\right)$. Even though the MMR spiked in the winter of 1918, with a strong declining trend and a shorter duration of the pandemic, several of the regional $\mathrm{MMR}_{1918}$ are still less than $\mathrm{MMR}_{1917}$, leaving this exercise less informative.
} 
height cutoffs (i.e., below the 5 percentile and above the $75^{\text {th }}$ percentile) to examine whether the reduction in height comes from a specific part of height distribution. We find that for males, the increase in maternal mortality rates (MMR) would increase the probability of being stunted (below the $5^{\text {th }}$ percentile) as well as reduce the likelihood of being above $75^{\text {th }}$ percentile. That suggests that the flu pandemic impacted height negatively for males throughout the entire distribution. In contrast, we find that for female, an increase in MMR reduces one's probability of being stunted while having a negative insignificant impact on the likelihood of being taller than the $75^{\text {th }}$ percentile. This interesting pattern can be due to positive selection. The issue of selection is stronger for female than male given that the average years of education for female is about 1.88 years (while male's average education is 4.73 years) and this height information was collected some time during $2^{\text {nd }} / 3^{\text {rd }}$ grade for the 1919 birth cohorts at school. It is likely the selected females who stay in school to complete $2^{\text {nd }} / 3^{\text {rd }}$ grade are healthier than the ones who dropped out of school.

[Insert Table 2 here]

\section{Educational Outcome-Time Series}

In this subsection, we attempt to replicate Almond's (2006) approach on education outcomes with the 1980 Taiwan Census. We have chosen the 1980 Census and the specific education outcome since the 1980 census was the earliest census that is available to researchers, and the 1980 census does not provide direct income/wealth measures, nor health measures. We present some time-series evidence examining the departure of pandemic birth cohorts from the surrounding cohorts in education outcomes.

In accordance with the fetal origins hypothesis, we would expect that those who were in utero during the peak of the pandemic (born between December 1918 and August 1919 and between December 1919 and September 1920) would be affected to a greater extent than those who were born just before the pandemic and nine months after the pandemic. We modify Almond’s (2006) specification to accommodate the two pandemic waves and to incorporate regional characteristics and region-specific time trends as below:

$$
y_{i j t}=\alpha+\beta_{1} * I(Y O B=1919)_{i j t}+\beta_{2} * I(Y O B=1920)_{i j t}+\text { Female }_{i}
$$




$$
+\sum_{j} \text { Region Fixed Effects }_{j}+\sum_{j} \text { Region }_{j} * \text { Time }_{t}+\varepsilon_{i j} \text {-Equation (1), }
$$

where $y_{i j t}$ is the education outcome for individual $\mathrm{i}$ in region $\mathrm{j}$ born in year t. I(.) denotes an indicator function whether one's year of birth is in the given year. Female $e_{i}$ indicates whether individual $i$ is female. The data include those who were born between 1916 and $1926 .^{21}$

The key here is examining whether the pandemic cohorts demonstrate any departure from linear trends. Estimates of $\beta_{1}$ and $\beta_{2}$ are reported in Table 3, Panels B and C, for men and women, respectively. Our estimate suggests a 1.8 percent drop $(-0.083 / 4.729=0.018)$ in years of education for the 1919 male birth cohort, while Almond (2006) finds a 1.4 percent drop in years of education. Another interesting finding is that coefficients for 1920 are mostly smaller than coefficients for 1919. This is what we expected from our discussion in Section III. ${ }^{22}$

[Insert Table 3 here]

Taiwan’s 1980 census provides other outcomes including labor force participation and housing conditions. We find that the 1919/1920 birth cohorts are less likely to be currently employed. However, the interpretations of these outcomes are not straightforward. The relevant birth cohorts (1919) were 60, which is older than the average retirement age in Taiwan, 55. It is unclear whether remaining in the labor force at age 60 is in fact desirable. It can be that one is not healthy enough, and thus she has to leave the labor force; alternatively, it can be that she has saved enough for retirement and thus is able leave the labor force. As for housing conditions, it is a norm in Taiwan that the elderly live with and are supported by their children upon retirement. Housing is a common form of inheritance. One’s housing condition may not only reflect the relevant cohorts' wealth, but rather may reflect one’s family wealth (be it one’s father's, or his children's, wealth). For brevity, these regression results are available in the web appendix.

\footnotetext{
${ }^{21}$ In the web appendix, we present a few robustness checks: first, the 1920 birth cohort dummies are removed from the regressions; second, we change cohort windows to 1915-1927 and 1917-1925; third, we add quadratic time trends; lastly, calendar of months fixed effects are included; last, price of rice (at region-year) level are included.

${ }^{22}$ Since we can identify the exact months when influenza death tolls peaked-in November/December 1918 and December/January 1919 — and we know the birth month, we can further examine whether influenza exposure during different trimesters and different waves could have differential impacts. There is no obvious pattern as to which trimester is most important in order for the in utero environment to have a long term impact. The specification and the results are available in the web appendix.
} 


\section{Regional Variation in Maternal Mortality Rate}

Another way to gauge the effect of influenza on education outcomes is to explore the regional-time variations in influenza severity.

We estimate the following regression:

$$
y_{i j t}=\alpha_{i j t}+\beta_{1} * \text { WeightedMMR } R_{i j t}+\beta_{2} * \text { Female }_{i}+v_{j}+\varepsilon_{i j t} \text {-Equation (2), }
$$

where $i$ is the individual, $j$ is the birth region, and $t$ is the birth year-month. ${ }^{23}$ The main coefficient of interest is $\beta_{1}$ on MMR, which approximates the health environment faced by the fetus. The MMR measures are available either at annual regional levels or monthly aggregate levels. There are various ways to construct the appropriate MMR for individual $i$, which we will explore in the robustness check section. First, we estimate Equation 3 with regional-annual MMR and calculate the weighted MMR in which weight is determined based on months of in utero exposure in a given year. For example, if one is born in June 1919, then the weighted MMR would be the weighted average between two-thirds of 1919 MMR and one-third times 1918 MMR. The results are reported in Table 4, Row 1. We find that a 1 percentage point increase in MMR results in a reduction in the years of education by 1.891 years. Next, infant mortality rate is added to capture the environment during the individual's infancy since this could also affect their later developmental outcomes. However, one should be cautious in interpreting this coefficient as causal. This is a period during which Taiwan had experienced an overall improvement in educational attainment and public health, so it is essential to control for a linear time trend. Moreover, this improvement in education can vary across regions, so a set of region-specific time trends is included in the specifications. Next, we include regional time trends, the results of which are reported in Row 3. This would be our preferred

\footnotetext{
${ }^{23}$ In the Taiwanese Census, birth place is reported at county level. We then match it to region level, as defined in 1919. Following regional-variation analysis in Almond (2006), we use fewer birth cohorts in this part of analysis. The birth cohorts included are 1917 to 1922. We exclude the 1916 cohorts, since we also noticed that there was a malaria outbreak in 1916. For the purpose of testing the fetal origin hypothesis, whether the increase of MMR was driven by malaria outbreaks or influenza probably does not affect the interpretation. However, the main identification of the paper is to exploit the variation of maternal mortality rates caused by the flu pandemic, so we decide to omit 1916 data in this set of analysis. In the web Appendix we provide various robustness checks including changing cohort windows by extending one more year in both directions, and the results are consistent.
} 
specification throughout the remainder of this paper. Once we control for the time trend, we find that the coefficient reduces by almost half. Every 1 percentage point increase in MMR would reduce the years of education by 0.865 years $(0.865 / 2.89=30$ percent $)$. Compared to Almond's (2005) finding of 0.947 year $(0.947 / 10.7=8.8$ percent $)$, while similar in absolute scale, the relative impact is much greater in Taiwan than in the United States. In Row 4, we use a lag regional-annual MMR from the previous year. In Row 5, we include sanitation expenditure, educational spending seven years later (when the cohort reaches the age to enter elementary school), and agriculture GDP per capita at the region-year level. This could capture some additional regional variations that cannot be eliminated by the region-specific time trend and region fixed effect. In Row 6, we use the mean of aggregate-monthly MMRs of the nine months prior to the birth; e.g., if one is born in September 1918, the average monthly MMR is the mean from monthly MMR from January-September $1918 .^{24}$

[Insert Table 4 Here]

[Insert Table 5 Here]

Table 5 reports coefficient estimates for several different setups for sensitivity analyses, using Equation 3 with regional-specific time trends. The first two rows report results for males and females separately. Overall, the negative effect of maternal mortality is sustained in both genders. In addition, the coefficients for the male subsample are slightly larger than their female counterparts. The gender difference may be due to the fact that, compared to males, very few females (fewer than 3 percent) have achieved an educational level higher than junior high school. Row 3 reports the results excluding Hualien and Taitung, the two eastern regions with sparse populations that were less affected by the 1918 influenza due to difficulties in transportation. In footnote 18, we mention that Taipei, Tainan, and Taidong saw exposures to cholera in 1919 that resulted in mortality rates but very few survivors. We exclude these regions from our analysis in Row 4. In Row 5, quarter-of-birth fixed effects are included. One can see that the sizes of coefficients are similar but they are less precisely estimated. Overall, the results from various

\footnotetext{
${ }^{24}$ We only report linear probability results for simplicity. In the web Appendix, we report the regression results with probit estimates.
} 
robustness checks are similar to our baseline results in Table 4, Row 2.

How large was the effect of influenza on educational attainment? Based on our estimates that the MMR increased 0.4 percentage points during the peak of 1918 pandemic, and the coefficient of maternal mortality on education years is -0.865 , it reduces years of education by about 12.0 percent $(0.4 * 0.865 / 2.89=0.12)$. Compared with Almond (2006), who obtained only a $2-3$ percent decrease in years of education, the 1918 influenza asserted a larger impact on Taiwan. ${ }^{25}$ Besides the fact that MMR is a proxy for in utero environment, maternal deaths can also have a direct effect on the surviving children. We do a back-of-the-envelope calculation estimating the direct effect, and it suggests that the direct effect would only lower the years of education by 0.01 year ( 0.26 percent) ${ }^{26}$

\section{Health Attainment in Old Age}

The Barker hypothesis also suggests that fetal influenza exposure can affect health conditions later in life. We investigate this claim by using the 1989 Survey of Health and Living Status of the Elderly in Taiwan and present the results in Table 6. The model specification is the same as for Equation 3 with region-specific time trends and infant mortality rates. In Panel A, linear probability models are presented and in Panel B, marginal effects from probit model are presented. ${ }^{27}$

As the results in Table 6 Panel A indicate, we find that an increase in MMR increases an individual's probability of having a respiratory disease (including asthma, bronchitis, and other breathing related diseases), diabetes, and kidney disease. These findings are important since both Mazumder et al. (2010) and Garthwaite (2009) use the National Health Interview Survey, but neither can examine respiratory

\footnotetext{
${ }^{25}$ Our point estimate is very similar to Almond's (2006). The only difference is that the baseline education level is much lower in Taiwan than the United States. Thus, it appears to have a bigger impact.

${ }^{26}$ Assuming that all children who lost their mother (during labors) receive zero years of education, we would find the direct impact of increasing MMR by 0.4 percentage points, which would lower years of education by only 0.01 years ( 0.04 percent) $(0.004 * 0+0.996 * 2.89=2.88)$.

${ }^{27}$ In this dataset, although birth month was collected in the survey, the statistical agency that houses the data is reluctant to share the birth month information. Therefore we only know whether an individual was born in the first or the second half of the year. For those who were born between January and June of any given year, we assign to them the maternal mortality rates from the previous year for their region. For those who were born between July and December, we assign them the maternal mortality rates from that year.
} 
illness due to data limitations. Based on the probit specification, we also find that an increase in MMR increases the likelihood of circulatory disease which is similar to the finding in Mazumder et al. (2010).

[Insert Table 7 here]

\section{Discussion and Conclusion}

Using MMR as a proxy measuring the degree of exposure, and combining several historical and current datasets in Taiwan, we find that exposure to 1918 influenza while in utero has a profound adverse effect on both short-term and long-term health and cognition outcomes. The pandemic cohort was shorter during childhood and adolescence, had less education and a higher chance of having various health issues, including kidney disease, cardiovascular disease, respiratory problems, and diabetes. This paper provides additional evidence supporting the fetal origins hypothesis.

Other than the height outcome which was measured during childhood and adolescence, one should note that most other outcomes were measured either in 1980 or 1989, when the relevant cohorts are in their 60s or early 70s. Attrition is certainly a valid concern. Given that the weaker or less healthy members are less likely to survive until 1980, a negative effect would be estimated on a positively selected sample, thus our regression results provide a lower bound of the true effects.

Our time-series analysis examines the impact of two waves of flu pandemic in Taiwan (the first wave in the winter of 1918 and the second wave in the winter of 1919-1920). Although there was a higher influenza-related death toll in the second wave than the first wave, based on the information collected, the second wave was more virulent and had a lower infection rate than the first wave, and the influenza deaths toll for child-bearing-age females between ages 20-35 were also lower in 1920 than in 1918 (Hsieh 2009; Taiwan Population Dynamics Statistics 1921). In our time-series regression analysis, we find a weaker impact for 1920 than 1918 when we examine the population as a whole. This analysis also suggests that, in future research that exploits a natural experiment similar to the influenza pandemic, if maternal infection rate or death tolls of pregnancy-age women are not available, MMR may be a better proxy than overall death tolls. 


\section{References}

1989 Survey of Health and Living Status of the Elderly (中老年身心社會生活狀况長期追蹤調查) (1989). Health Promotion Administration, Ministry of Health and Welfare. [in Chinese]

Almond, D. (2005). Is the 1918 influenza pandemic over? Long-Term effects of in utero influenza exposure in the Post-1940 U.S. population. Working Paper.

Almond, D. (2006). Is the 1918 influenza pandemic over? Long-Term effects of in utero influenza exposure in the Post-1940 U.S. population. Journal of Political Economy, 114(4), pp. 672-712.

Almond, D., Chay, K., \& Lee, D. (2005). The cost of low birth weight. Quarterly Journal of Economics, 120(3),1031-1083.

Almond, D., \& Currie, J. (2011a). Human Capital Development Before Age Five. in Orley Ashenfelter and David Card (Eds.), The Handbook of Labor Economics, 4b. Amsterdam: Elsevier Science B.V.

Almond, D. \& Currie, J. (2011b). Killing Me Softly: The Fetal Origins Hypothesis. Journal of Economics Perspectives.25(3), 153-172.

Almond, D., \& Edlund, L. (2007). Trivers-Willard at birth and one year: Evidence from US natality data 1983-2001. Proceedings of the Royal Society B: Biological Sciences, 274(1624), 2491-2496.

Almond, D., Edlund, L., \& Palme, M. (2009). Chernobyl's subclinical legacy: Prenatal exposure to radioactive fallout and school outcomes in Sweden. The Quarterly Journal of Economics, 124(4), pp. 1729-1772.

Almond, D., \& Mazumder, B. (2005). The 1918 influenza pandemic and subsequent health outcomes: An analysis of SIPP data. The American Economic Review, 95(2, Papers and Proceedings of the One Hundred Seventeenth Annual Meeting of the American Economic Association, Philadelphia, PA, January 7-9, 2005), pp. 258-262.

Almond, D., and Mazumder, B.(2011) Health Capital and the Prenatal Environment: The Effect of Ramadan Observance during Pregnancy. American Economic Journal: Applied Economics, 3(4): 5685.

Angrist, J. D., \& Pischke, J. S. (2008). Mostly harmless econometrics: An empiricist's companion. Princeton university press.

Ansart, S., (2009), Mortality burden of the 1918-1919 influenza pandemic in Europe, Influenza and other Respiratory Viruses, 3(3), 99-106.

Atladóttir, H. O., Thorsen, P., Østergaard, L., Schendel, D. E., Lemcke, S., Abdallah, M., \& Parner, E. T. (2010). Maternal infection requiring hospitalization during pregnancy and autism spectrum disorders. Journal of autism and developmental disorders, 40(12), 1423-1430.

Barker, D. J. P. (1990). The fetal and infant origins of adult disease: The womb may be more important than the home. BMJ: British Medical Journal, 301(6761), p. 1111.

Barker, D. J. P. (1992). Fetal and infant origins of adult disease. BMJ Books, 
Barker, D. J. P. (1998). Mothers, babies and health in later life, $2^{\text {nd }}$ edition Edinburgh: Churchill Livingstone.

Barker, D. J. P., \& Osmond, C. (1987). Death rates from stroke in England and wales predicted from past maternal mortality. British Medical Journal (Clinical Research Edition), 295(6590), pp. 83-86.

Barker, D., Eriksson, J., ForsÃn, T., \& Osmond, C. (2002). Fetal origins of adult disease: Strength of effects and biological basis. International Journal of Epidemiology, 31(6), 1235-1239.

Barreca, A. (2010). The long-term economic impact of in utero and postnatal exposure to malaria. Journal of Human Resources, 45(4): 865-892

Behrman, J. R., \& Rosenzweig, M. R. (2004). Returns to birth weight. The Review of Economics and Statistics,86(2), pp. 586-601.

Black, S. E., Devereux, P. J., \& Salvanes, K. G. (2007). From the cradle to the labor market? the effect of birth weight on adult outcomes. The Quarterly Journal of Economics, 122(1), 409-439.

Boardman, J., Powers, D. A., Padilla, Y. C., \& Hummer, R. A. (2002). Low birth weight, social factors, and developmental outcomes among children in the united states. Demography, 39(2), pp. 353-368.

Bozzoli, C., Deaton, A., \& Quintana-Domeque, C. (2009). Adult height and childhood disease. Demography, 46(4), 647-669.

Brown, A. S., Begg, M. D., Gravenstein, S., Schaefer, C. A., Wyatt, R. J., Bresnahan, M., et al. (2004). Serologic evidence of prenatal influenza in the etiology of schizophrenia. Archives of General Psychiatry, 61(8), 774-780.

Brown, R., (2011). The 1918 U.S. influenza pandemic as a natural experiment, revisited. .Unpublished

Cameron, A. C., Gelbach, J. B., \& Miller, D. L. (2008). Bootstrap-based improvements for inference with clustered errors. Review of Economics and Statistics, 90(3), 414-427.

Case, A., Fertig, A., \& Paxson, C. (2005). The lasting impact of childhood health and circumstance. Journal of Health Economics, 24(2), 365-389.

Case, A., Lubotsky, D., \& Paxson, C. (2002). Economic status and health in childhood: The origins of the gradient. The American Economic Review, 92(5), pp. 1308-1334.

Case, A., \& Paxson, C. (2008). Height, health, and cognitive function at older ages. The American Economic Review, 98(2), 463-467.

Census Bureau (1924) Statistical Abstract of the United States http://www2.census.gov/prod2/statcomp/documents/1924-01.pdf

Chen, Y. \& Zhou, L.(2007). The long-term health and economic consequences of the 1959-1961 famine in China. Journal of Health Economics, 26(4), 659-681. 
Chou, W. (1995). Being forgotten in history: The experience of Taiwanese soldiers during Japanese rule. [歷史的記憶與遺忘：「臺籍日本兵」之戰爭經驗的省思] Current, (107), 34-49.

Conley, D. \& Bennett, N. G. (2000). Is biology destiny? birth weight and life chances. American Sociological Review, 65(3), pp. 458-467.

Currie, J. (2011). "Inequality at Birth: Some Causes and Consequences." American Economic Review, 101(3): 1-22.

Currie, J., \& Vogl, T. (2013). Early-life health and adult circumstance in developing countries. Annual Review of Economics, 5(7), 1-7.36.

Ding, K. C. (2008). 1918-1920 H1N1 flu pandemic in Taipei. (in Chinese) [1918-20 年台北地區的 H1N1 流感疫情] Life Science News, 12, 141-175.

Dynamic Census of the Taiwanese Population (台灣人 $\square$ 動態統計)(1916-1925). Japanese Colonial Government in Taiwan. [in Japanese]

Ericson, A. and Kallen, B. 1998. "Very low birthweight Boys at Age 19.” Archives of Disease in Childhood - Fetal and Neonatal Edition 78 (May): F171-4.

Erkoreka, A. (2010). The Spanish influenza pandemic in occidental Europe (1918-1920) and victim age. Influenza and other respiratory viruses, 4(2), 81-89.

Field, E., Robles,O., \& Torero, M. (2009). Iodine Deficiency and Schooling Attainment in Tanzania. American Economic Journal: Applied Economics, 1(4): 140-69.

Garthwaite, C. (2009). The effect of in-utero conditions on long term health: Evidence from the 1918 spanish flu pandemica. Unpublished

Glynn, L. M., Wadhwa, P. D., Dunkel-Schetter, C., Chicz-Demet, A., \& Sandman, C. A. (2001). When stress happens matters: Effects of earthquake timing on stress responsivity in pregnancy. American Journal of Obstetrics and Gynecology, 184, 637-642.

Hack, M., Flannery, D. J., Schluchter, M., Cartar, L., Borawski, E., \& Klein, N. (2002). Outcomes in young adulthood for very-low-birth-weight infants. N Engl J Med, 346(3), 149-157.

Haines, M.,(2001). The Urban Mortality Transition in the United States, 1800-1940. NBER Historical Working Paper No. 134

Hsieh, Y. H. (2009). Excess deaths and immunoprotection during 1918-1920 influenza pandemic, Taiwan. Emerging infectious diseases, 15(10), 1617.

Health statistics for school students. (昭和二年學校生徒及兒童身體檢查統計書)(1927). Japanese Colonial Government in Taiwan.

Huizink AC, Robles de Medina PG, Mulder EJ, Visser GH, Buitelaar JK. Stress during pregnancy is associated with developmental outcome in infancy. J Child Psychol Psychiatry. 2003;44:810-818 
Johnson, N. \& Mueller, J. (2002). Updating the accounts: global mortality of the 1918-1920 "Spanish" influenza pandemic. Bulletin of the History of Medicine 76:105-15

Johnson, R. C., \& Schoeni, R. F. (2011). The influence of early-life events on human capital, health status, and labor market outcomes over the life course. The B.E.Journal of Economic Analysis \& Policy, 11(3), 3.

Kawana , A. et al (2007). Spanish Influenza in Japanese Armed Forces, 1918-1920 Emerging Infectious Diseases 2007 April; 13(4): 590-593.

Kelly, E. (2011). The Scourge of Asian Flu: In utero Exposure to Pandemic Influenza and the Development of a Cohort of British Children. Journal of Human Resources 46(4), 669-694.

Konje, J. C., Bell, S. C., Morton, J. J., De Chazal, R., \& Taylor, D. J. (1996). Human fetal kidney morphometry during gestation and the relationship between weight, kidney morphometry and plasma active renin concentration at birth. Clinical Science, 91, 169-175.

Langley-Evans, S. C. (2001). Fetal programming of cardiovascular function through exposure to maternal undernutrition. Proceedings of the Nutrition Society, 60(04), 505-513.

Lauderdale, D. S. (2006). Birth outcomes for Arabic-named women in California before and after September 11. Demography, 43, 185-201.

Lee, D. S. (2009). Training, wages, and sample selection: Estimating sharp bounds on treatment effects. Review of Economic Studies, 76(3), 1071-1102.

LeWinn, K. Laura R Stroud, Beth E Molnar, James H Ware, Karestan C Koenen, and Stephen L Buka (2009). Elevated maternal cortisol levels during pregnancy are associated with reduced childhood IQ. International Journal of Epidemiology, 38(6):1700_1710

Lin, M., \& Liu, J. (2009). Do lower birth weight babies have lower grades? twin fixed effect and instrumental variable method evidence from Taiwan. Social Science \& Medicine, 68(10), 1780.

Lleras-Muney, A. (2005). The Relationship between Education and Adult Mortality in the U.S. Review of Economic Studies, 72(1), 189-221.

Mazumder, B., Almond, D., Park, K., Crimmins, E. M., \& Finch, C. E. (2010). Lingering prenatal effects of the 1918 influenza pandemic on cardiovascular disease. J Dev Orig Health Dis., 1(1), 26-34.

Mceniry, M., and Palloni, A.(2010) Early Life Exposures and the Occurrence and Timing of Heart Disease Among the Older Adult Puerto Rican Population. Demography, 47(1), $23-43$.

Neelsen, S. \& Stratmann, T, 2011. Effects of prenatal and early life malnutrition: Evidence from the Greek famine. Journal of Health Economics, 30(3), 479-488.

Neelsen, S. \& Stratmann. T. (2012). Long-Run Effects of Fetal Influenza Exposure: Evidence from Switzerland. Social Science and Medicine, 74(1), 58-66.

Nelson, R. E. (2010). Testing the fetal origins hypothesis in a developing country: Evidence from the 1918 influenza pandemic. Health Economics, 19(10), 1181-1192. 
Noymer, A., \& Garenne, M. (2000). The 1918 influenza epidemic's effects on sex differentials in mortality in the united states. Population and Development Review, 26(3), 565-581.

Oreopoulos, P., Stabile, M., Walld, R., \& Roos, L. L. (2008). Short-, medium-, and long-term consequences of poor infant health: An analysis using siblings and twins. Journal of Human Resources, 43(1)

Ozanne, S. E., \& Hales, C. N. (2004). Lifespan: Catch-up growth and obesity in male mice. Nature, 427(6973), 411-412.

Patterson, P. H. (2011). Maternal infection and immune involvement in autism.Trends in molecular medicine, 17(7), 389-394.

Richard, S.A. N. Sugaya, L. Simonsen, M. A. Miller and C. Viboud (2009). A comparative study of the 1918-1920 influenza pandemic in Japan, USA and UK: mortality impact and implications for pandemic planning. Epidemiology and Infection, 137, pp 1062-1072

Royer, H. (2009). Separated at girth: US twin estimates of the effects of birth weight. American Economic Journal: Applied Economics, 1(1), pp. 49-85.

Ru, H. Y. (2010). Facing the Japanese: Colonialism, Modernization, and Epidemic Liver Disease in Truku Society, 1895-1945.

Rubinstein, M. (Ed.). (1999). Taiwan: A new history M E Sharpe Inc.

Sun, W. (2010). The governance meanings of the major epidemic prevention in Taiwan during the early stage under Japanese rule. (Master Thesis, National University of Tainan).

Taipei County Statistical Books (臺北州統計書) (1929-1938).

Taiwan Medical Association Journal 1919, 1921 臺灣醫學會雜誌

Taiwan Population and housing census ( 戶口及住宅普查) Directorate General of Budget, Accounting and Statistics, Taiwan, 1980 Survey.

Thomas, D. (1994). Like father, like son; like mother, like daughter: Parental resources and child height. The Journal of Human Resources, 29(4, Special Issue: The Family and Intergenerational Relations), pp. 950-988.

Torche F. (2011) The Effect of Maternal Stress on Birth Outcomes:Exploiting a Natural Experiment Demography (2011) 48:1473-1491

Tsai, C. H. (2005). Rulers during pandemic flu: Two civil governor during japanese colonization. [世紀流 感下的統治者一日治時期的兩位總督] Chi-Nan University Electronic Journal, 33

Ward, Courtney (2011) “The long-term economic effects of school immunization mandates: does prenatal exposure to state school immunization policy impact health and well-being in later life?” Unpublished Manuscript. 
Figure 1: Quarterly Influenza-Related Death Tolls in Taiwan 1916-1926

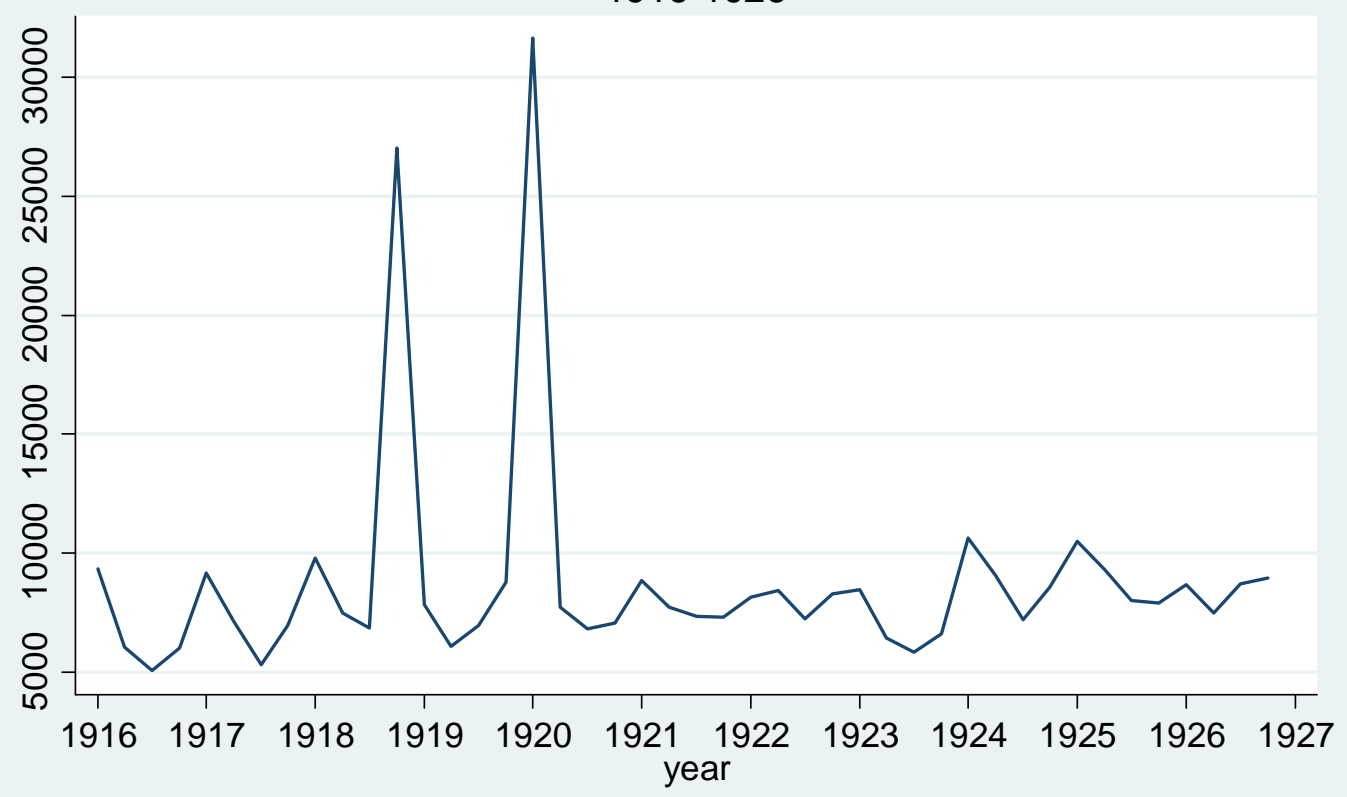

Source: Dynamic Census of the Taiwanese Population 1916-1926

Figure 2: Influenza-Related Death Tolls for Female

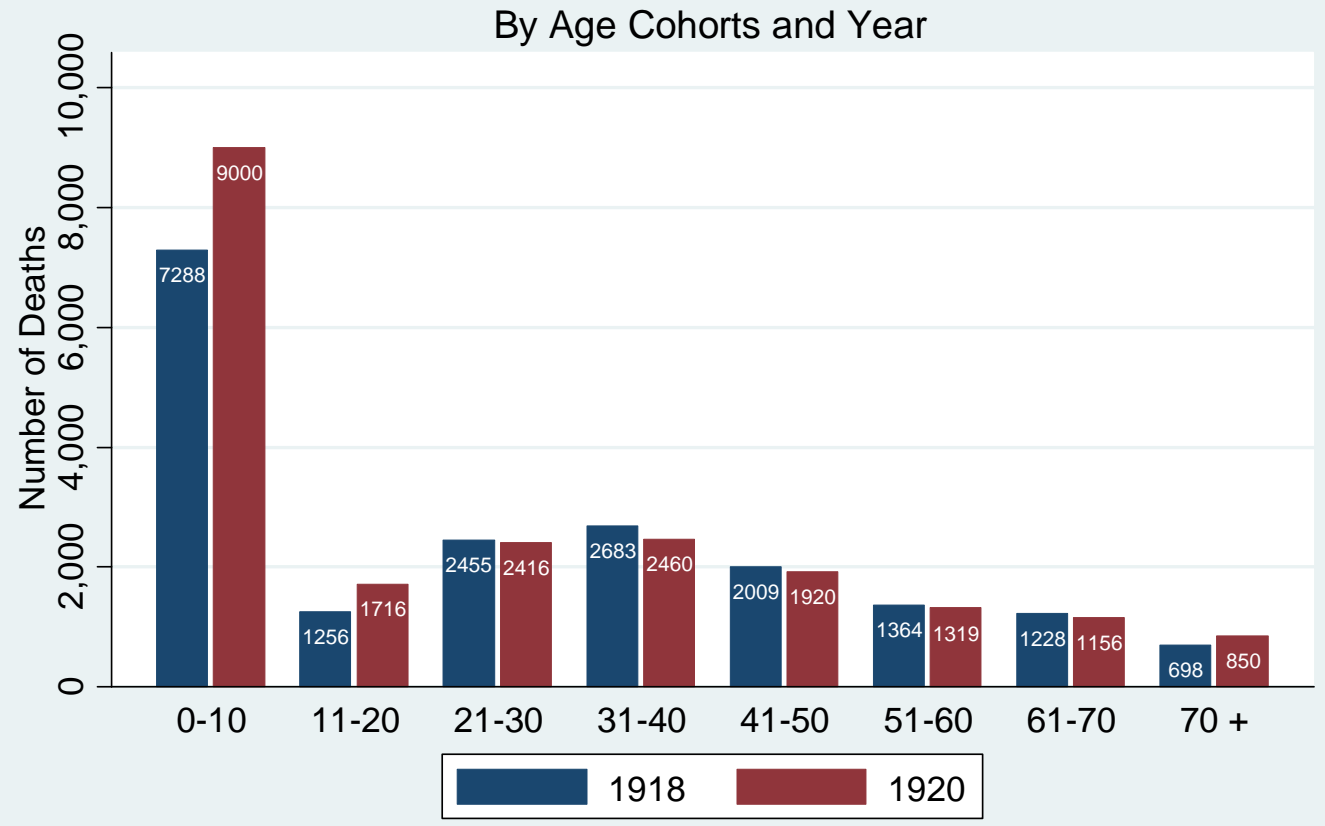

Source: Dynamic Census of the Taiwanese Population 1918 \& 1920 
Figure 3: Residual Maternal Mortality Rates in Taiwan 1916-1926

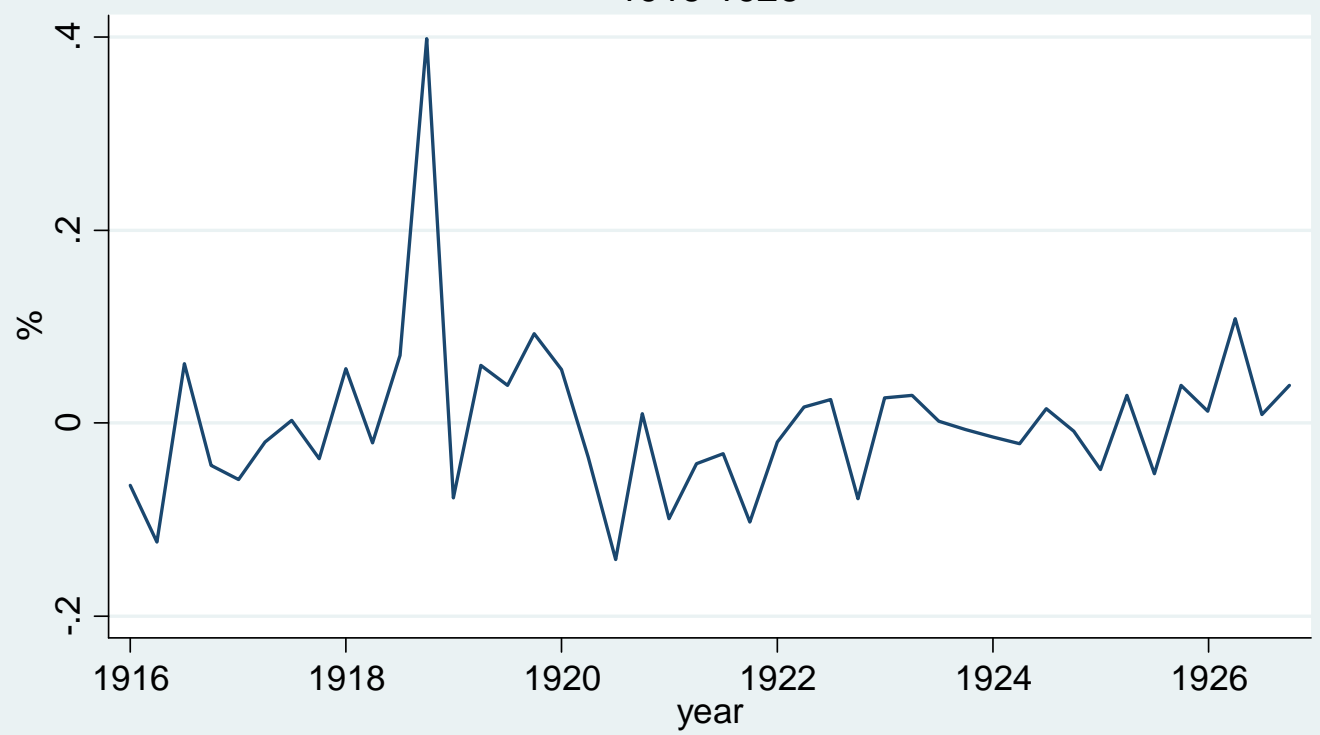

Residuals are estimated based on a regression including the linear and quadratic term of birth year, malaria, and cholera death tolls.

Source: Dynamic Census of the Taiwanese Population 1916-1926

Figure 4: Average Height of Male Students Age 13-17, born in 1917-1921

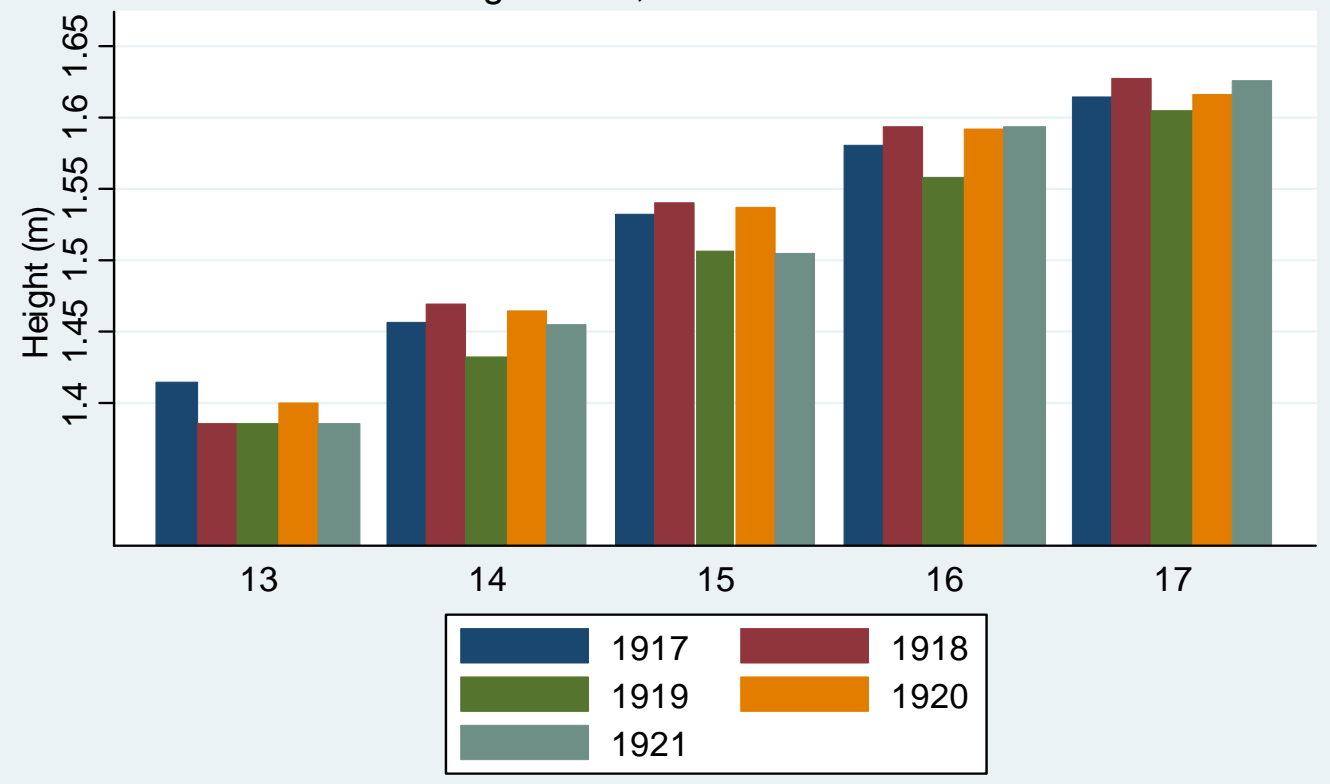

Source: Taipei County's Statistical Books, 1929-1938 
Table 1A: Individual-Level Summary Statistics from 1980 Census for 1916-1926 Birth Cohorts

\begin{tabular}{|c|c|c|c|}
\hline & all & male & female \\
\hline \multirow[t]{2}{*}{ Years of Education } & 3.253 & 4.729 & 1.880 \\
\hline & (3.849) & $(3.967)$ & (3.169) \\
\hline \multirow[t]{2}{*}{ Elementary School Completion (\%) } & 46.09 & 65.52 & 28.00 \\
\hline & $(0.498)$ & $(0.475)$ & $(0.449)$ \\
\hline \multirow[t]{2}{*}{ Middle School Complete (\%) } & 9.64 & 15.49 & 4.21 \\
\hline & $(0.295)$ & $(0.362)$ & $(0.201)$ \\
\hline \multirow[t]{2}{*}{ High School Completion (\%) } & 5.08 & 8.22 & 2.16 \\
\hline & $(0.220)$ & $(0.274)$ & $(0.145)$ \\
\hline \multirow[t]{2}{*}{ College Completion (\%) } & 1.49 & 2.73 & 0.33 \\
\hline & $(0.121)$ & $(0.163)$ & $(0.578)$ \\
\hline \multirow[t]{2}{*}{ Female (\%) } & 51.8 & & \\
\hline & $(0.500)$ & & \\
\hline Observations & 870468 & 390,910 & 450,914 \\
\hline \multicolumn{4}{|c|}{ Table 1B: Regional-Year-Level Summary Statistics } \\
\hline & Mean & Min & Max \\
\hline Maternal mortality rate (\%) & 0.47 & 0.11 & 1.00 \\
\hline Infant mortality rate (\%) & 16.55 & 11.4 & 24.74 \\
\hline 7-year Lagged Education Expenditure (per capita) ${ }^{1}$ & 1.188 & 0.131 & 3.584 \\
\hline Government Sanitary Expenditure (per capita) & 0.11 & 0.006 & 0.635 \\
\hline Agriculture GDP per capita & 41.51 & 18.58 & 71.64 \\
\hline
\end{tabular}

1. Usually one enters school when he/she turns 7. Thus the reported education expenditure is lagged 7 years. It is imputed using total government education expenditure for a given year/region divided by total population in a given year/region. Note: Standard deviations are reported in parentheses. 
Table 2: Effect of Maternal Mortality Rate on Height in the 1927 Height Report of School Children

(1)

(2)

(3)

(4)

Dependent Variable

\begin{tabular}{|c|c|c|c|c|c|}
\hline & \multirow[b]{2}{*}{$\frac{\text { Mean }}{\underline{(\mathrm{cm})}}$} & \\
\hline & & height $(\mathrm{cm})$ & $\begin{array}{c}\text { height } \\
\text { (z-score) }\end{array}$ & $\begin{array}{c}\text { Stunting } \\
\text { (height }<=5 \text { th } \\
\text { percentile) }\end{array}$ & $\begin{array}{c}\text { (height }>=75 \\
\text { percentile) }\end{array}$ \\
\hline All & 119.5 & $-4.029 *$ & -1.524 & 0.219 & $-0.390 * *$ \\
\hline$p$-value & & [0.072] & [0.116] & [0.212] & [0.039] \\
\hline Male & 120.8 & $-4.410 * * *$ & -1.509 & $0.398 * *$ & $-0.458 * *$ \\
\hline$p$-value & & [0.000] & [0.144] & [0.024] & [0.029] \\
\hline Female & 118.0 & -3.810 & -1.347 & $-0.286^{*}$ & -0.330 \\
\hline$p$-value & & [0.424] & [0.112] & {$[0.080]$} & [0.121] \\
\hline
\end{tabular}

Notes: Wild bootstrap $\mathrm{p}$-values with 500 repetitions and $\mathrm{p}$-values from clustering at regional level are in brackets. * significant at $10 \%$ level, $* *$ at $5 \%$ level and $* * *$ at $1 \%$ level based on wild bootstrap p-values. Stunting is a dummy variable it equals 1 if the height is lower than 5 percentile for given age-gender group. The dependent variable in Column 4 indicates whether one's height is above 75 percentile for a given age-gender group. Each coefficient is from a separate regression. There are a total of 83,211 male students and 31,039 female students ranging from age 7 to age 10 . Maternal mortality rate (ranging from 0 to 100) is imputed as an average of region-specific maternal mortality rate from the year (1927-age) and the year prior to that. Age is included in regressions for Column 1, gender dummies are included in regressions for all population (row 1), and infant mortality rate, region dummies, and region-specific time trends are included in all regressions. 
Table 3: Departure in Education Outcomes of 1919 and 1920 Birth Cohorts

\begin{tabular}{|c|c|c|c|c|}
\hline & (1) & $(2)$ & (3) & (4) \\
\hline & Years of & Elementary & & High \\
\hline VARIABLES & Schooling & School & Middle School & School \\
\hline \multicolumn{5}{|c|}{ Panel A: All (Male and Female) } \\
\hline Mean (Dependent Variable) & 3.253 & 0.461 & 0.096 & 0.051 \\
\hline 1919 Birth Cohort & $-0.080 * * *$ & $-0.007 * * *$ & $-0.005 * * *$ & $-0.005 * * *$ \\
\hline$p$-value from wild bootstrap & {$[0.000]$} & {$[0.000]$} & {$[0.000]$} & {$[0.000]$} \\
\hline 1920 Birth Cohort & $-0.058 * *$ & $-0.006 * *$ & $-0.004 * * *$ & $-0.002 * * *$ \\
\hline$p$-value from wild bootstrap & {$[0.024]$} & {$[0.028]$} & {$[0.000]$} & {$[0.004]$} \\
\hline \multicolumn{5}{|c|}{ Panel B: Male Only } \\
\hline Mean (Dependent Variable) & 4.729 & 0.655 & 0.155 & 0.082 \\
\hline 1919 Birth Cohort & $-0.083 * * *$ & $-0.004 *$ & $-0.008 * * *$ & $-0.008 * * *$ \\
\hline$p$-value from wild bootstrap & {$[0.000]$} & {$[0.040]$} & {$[0.000]$} & {$[0.000]$} \\
\hline 1920 Birth Cohort & $-0.052 *$ & -0.004 & $-0.004 * *$ & $-0.004 * *$ \\
\hline$p$-value from wild bootstrap & {$[0.084]$} & {$[0.156]$} & {$[0.012]$} & [0.020] \\
\hline \multicolumn{5}{|c|}{ Panel C: Female Only } \\
\hline Mean (Dependent Variable) & 1.880 & 0.280 & 0.042 & 0.022 \\
\hline 1919 Birth Cohort & $-0.077 * * *$ & $-0.009 * *$ & $-0.003 * *$ & $-0.002 * * *$ \\
\hline$p$-value from wild bootstrap & {$[0.004]$} & {$[0.016]$} & {$[0.012]$} & {$[0.000]$} \\
\hline 1920 Birth Cohort & $-0.062 * *$ & $-0.007^{*}$ & $-0.004 * * *$ & $-0.001^{*}$ \\
\hline $\mathrm{p}$-value from wild bootstrap & [0.048] & [0.068] & {$[0.000]$} & [0.064] \\
\hline
\end{tabular}

Notes: Panel A includes 870,468 observations. Panel B includes 419,544 observations.

Panel $C$ includes 450,914 observations. Wild bootstrap p-values with 500 repetitions and pvalues from clustering at regional level are in brackets. * significant at $10 \%$ level, ${ }^{* *}$ at $5 \%$ level and $* * *$ at $1 \%$ level based on wild bootstrap $p$-values. Birth cohorts included are 1916-1926. All models allow for correlation among observations within the same region. Gender, region dummies, and region-specific time trends are included. 


\begin{tabular}{|c|c|c|c|c|}
\hline & \multicolumn{4}{|c|}{ Dependent Variable } \\
\hline & (1) & $(2)$ & (3) & (4) \\
\hline & Years of & Elementary & Middle & High \\
\hline & Schooling & School & School & School \\
\hline Mean (Dependent Variable) & 2.89 & 0.41 & 0.08 & 0.04 \\
\hline \multicolumn{5}{|l|}{ (1): Estimate of Equation 3} \\
\hline weighted maternal mortality rates & $-1.891 * * *$ & $-0.248 * * *$ & $-0.074 * * *$ & $-0.044 * * *$ \\
\hline$p$-value from wild bootstrap & {$[0.004]$} & {$[0.004]$} & {$[0.004]$} & {$[0.004]$} \\
\hline \multicolumn{5}{|l|}{ (2): (1)+ Infant Mortality Rates } \\
\hline weighted maternal mortality rates & $-1.767 * * *$ & $-0.229 * * *$ & $-0.071 * * *$ & $-0.044 * * *$ \\
\hline$p$-value from wild bootstrap & {$[0.000]$} & {$[0.000]$} & {$[0.004]$} & {$[0.000]$} \\
\hline \multicolumn{5}{|l|}{ (3): (2) + Region-specific time trends } \\
\hline weighted maternal mortality rates & $-0.865 * *$ & -0.097 & $-0.042 * *$ & $-0.035^{*}$ \\
\hline$p$-value from wild bootstrap & {$[0.028]$} & {$[0.100]$} & [0.036] & {$[0.076]$} \\
\hline \multicolumn{5}{|l|}{ (4): (3) + MMR(t-1) } \\
\hline $\operatorname{MMR}(\mathrm{t}-1)$ & $-0.693 *$ & -0.084 & $-0.033 * *$ & $-0.024 * *$ \\
\hline$p$-value from wild bootstrap & {$[0.056]$} & {$[0.180]$} & {$[0.016]$} & {$[0.016]$} \\
\hline
\end{tabular}

(5): (3) + Government Sanitation Expenditure, Education Expenditure , and Regional GDP per cá $\begin{array}{lllll}\text { weighted maternal mortality rates } & -0.865 * & -0.102 & -0.039 * & -0.029\end{array}$ $\begin{array}{llll}p \text {-value from wild bootstrap } \quad[0.076] & {[0.152]} & {[0.056]} & {[0.104]}\end{array}$

(6): (3) + 9-Month Average MMR

$\begin{array}{lllll}\text { 9-month moving average MMR } & -1.223^{*} & -0.140 & -0.062 * * & -0.045^{* *} \\ \text { p-value from wild bootstrap } & {[0.072]} & {[0.348]} & {[0.028]} & {[0.040]}\end{array}$

$\left.\begin{array}{llll}p \text {-value from wild bootstrap } & {[0.072]} & {[0.348}\end{array}\right][0.028] \quad[0.040]$

Notes: $\mathrm{N}=445,987$. Each coefficient represents a result from a regression. Wild bootstrap $\mathrm{p}$ values with 500 repetitions and $p$-values from clustering at regional level are in brackets. * significant at $10 \%$ level, $* *$ at $5 \%$ level and $* * *$ at $1 \%$ level based on wild bootstrap $p$-values. Birth cohorts included are 1917-1922. All models allow for correlation among observations within the same region. Gender and region dummies are also included in all regressions. 
Table 5: Robustness Check of Maternal Mortality Rate on Educational Attainment

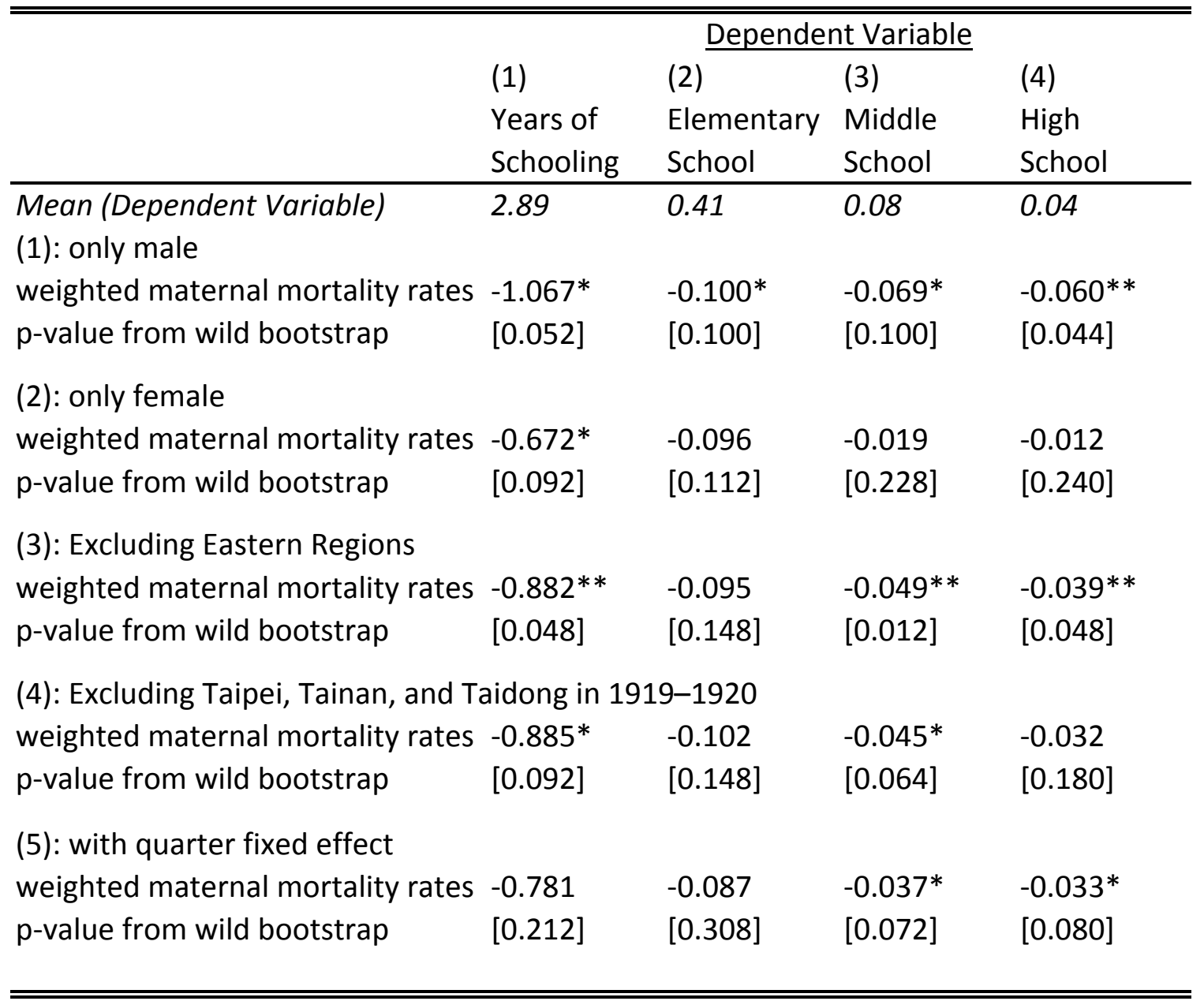

Notes: Each coefficient represents a result from a regression. Wild bootstrap p-values with 500 repetitions and $p$-values from clustering at regional level are in brackets. * significant at $10 \%$ level, $* *$ at $5 \%$ level, and $* * *$ at $1 \%$ level based on wild bootstrap pvalues. Birth cohorts from 1917-1922. All models allow for correlation among observations within the same region. Infant mortality rate, gender, region dummies, and region-specific time trends are also included in all regressions. 


\begin{tabular}{|c|c|c|c|c|c|c|}
\hline & $\begin{array}{l}\text { Kidney } \\
\text { Disease } \\
\text { (1) }\end{array}$ & $\begin{array}{l}\text { Vertigo } \\
\text { (Dizzy) } \\
\text { (2) }\end{array}$ & $\begin{array}{l}\text { Circulatory } \\
\text { disease } \\
\text { (3) }\end{array}$ & $\begin{array}{l}\text { Respiratory } \\
\text { disease } \\
\text { (4) }\end{array}$ & $\begin{array}{l}\text { Glaucoma } \\
\text { (5) }\end{array}$ & $\begin{array}{l}\text { Diabetes } \\
\text { (6) }\end{array}$ \\
\hline Mean (Dependent Variable) & 0.047 & 0.271 & 0.163 & 0.146 & 0.014 & 0.051 \\
\hline \multicolumn{7}{|c|}{ Panel A: Linear Probability Model } \\
\hline weighted maternal mortality rate & $0.271^{*}$ & 0.271 & 0.179 & $0.173^{\star \star}$ & 0.040 & $0.108^{*}$ \\
\hline$p$-value from wild bootstrap & {$[0.076]$} & [0.180] & [0.120] & [0.016] & [0.116] & [0.100] \\
\hline \multicolumn{7}{|c|}{ Panel B: Probit Model } \\
\hline weighted maternal mortality rate & $0.048^{\star \star \star}$ & 0.283 & $0.170^{*}$ & $0.176^{\star \star}$ & $0.007^{\star \star *}$ & $0.092^{\star *}$ \\
\hline $\mathrm{p}$-value from clustering & $(0.002)$ & $(0.149)$ & $(0.079)$ & $(0.038)$ & $(0.000)$ & $(0.014)$ \\
\hline \multicolumn{7}{|c|}{$\begin{array}{l}\text { Notes: } \mathrm{N}=1836 \text {. In Panel } \mathrm{A} \text {, wild bootstrap } \mathrm{p} \text {-values with } 500 \text { repetitions and } \mathrm{p} \text {-values from clustering at regiona } \\
\text { level are in brackets. In Panel } \mathrm{B}, \mathrm{p} \text {-values from clustering standard errors at regional level are in parentheses. } \\
\text { Marginal effects from probit model are reported. }{ }^{*} \text { significant at } 10 \% \text { level, }{ }^{* *} \text { at } 5 \% \text { level, and } * * * \text { at } 1 \% \text { level } \\
\text { based on p-values. Birthyear ranges from } 1916 \text { to } 1926 . \text { Infant mortality rate, gender, region dummies, and } \\
\text { region-specific time trends are also included in all regressions. }\end{array}$} \\
\hline
\end{tabular}

